\title{
COMMENTARY
}

\section{Clinical prediction rules for invasive candidiasis in the ICU: ready for prime time?}

\author{
Luis Ostrosky-Zeichner* \\ See related research by Hermsen et al., http://ccforum.com/content/15/4/R198
}

\begin{abstract}
Invasive candidiasis is a major source of morbidity and mortality in critically ill patients. The creation and validation of clinical prediction rules to identify patients at high risk has given clinicians access to advanced management strategies, such as targeted prophylaxis, pre-emptive therapy, and protocolized empirical therapy.
\end{abstract}

In the previous issue of Critical Care, Hermsen and colleagues [1] presented a validation of two clinical prediction rules for invasive candidiasis (IC) and propose a new one based on common risk factors found in ICU patients.

IC is the third to fourth most common cause of bloodstream infections in ICUs in the United States [2]. This infection is associated with substantial mortality $(40 \%)$ and increased healthcare costs (approximately $\$ 40,000)$ [3]. Considerable research has been undertaken to identify patients at high risk for this infection and may benefit from prophylaxis or early therapy strategies, such as pre-emptive therapy and empirical therapy $[4,5]$.

Hermsen and colleagues have attempted to validate two clinical prediction rules for IC in ICU patients in the setting of a case control study using contemporary patients from the Nebraska Medical Center. During the study period, the overall incidence of IC in patients with a length of stay $\geq 4$ days was $2.3 \%$, which is the typical incidence of IC seen in most ICUs in the US. Hermsen and colleagues selected patients with invasive candidiasis and matched them to three uninfected controls to validate the performance of the Paphitou [6] and OstroskyZeichner rules [7]. These two rules were originally constructed through retrospective chart reviews and logistic

*Correspondence: Luis.Ostrosky-Zeichner@uth.tmc.edu

Division of Infectious Diseases, University of Texas Medical School at Houston, 6431 Fannin, MSB 2.112, Houston, TX 77030, USA regression to identify high risk patients for a multicenter clinical trial of antifungal prophylaxis in the ICU setting. In their validation, Hermsen and colleagues found that the Paphitou rule had sensitivity approximately $40 \%$, specificity approximately $80 \%$, and an unusually low positive predictive value (PPV) with a negative predictive value (NPV) $>98 \%$. The Ostrosky-Zeichner rule had sensitivity approximately $70 \%$, specificity approximately $60 \%$, with similar PPV and NPV performance. They then proceeded to create their own prediction rule (NMC rule), which includes any broad-spectrum antibiotic use, central venous catheter (D1 to D3), abdominal surgery (D-7 to D3), immunosuppressants (D-7 to D0), total parenteral nutrition (D1 to D3) and mean pre-ICU length of stay. The performance of their rule was reported as sensitivity $84.1 \%$, specificity $60.2 \%$, PPV $4.7 \%$, NPV $99.4 \%$, and area under the receiver operating characteristic curve (AUC ROC) 0.770.

Although the NMC rule shows very attractive risk prediction performance, one must approach these results with caution due to two important limitations of this study. The first is that the rule was derived from a singlecenter retrospective chart review study and it was created and validated in the same population. That was the same problem the Paphitou rule encountered, as performance in the original single-center study was quite predictive, but when we attempted to validate it in a multicenter data set, the rule lost a significant amount of sensitivity and specificity. The second limitation is more technical, and it has to do with attempting to evaluate PPV and NPV in case-control studies with an artificially created 'incidence' of disease. In the case-control study the incidence of IC would be $25 \%$, which is 10 times higher than the incidence seen typically in patients who have an ICU length of stay $\geq 4$ days.

Nevertheless, the NMC rule is a welcome addition to a set of clinical prediction rules that are currently in various stages of validation in prospective studies, such as the Candida score [8,9] and the MSG rule [10]. One can envision a near future in which ICU patients are systematically screened for risk of IC while in the ICU, giving them access to antifungal prophylaxis or enhanced 
surveillance with biomarkers and pre-emptive therapy of early disease, or as Hermsen and colleagues also propose, these rules can also be used to determine patients who would be less likely to benefit from these interventions and thus to discontinue antifungal prophylaxis in the evolution of antifungal stewardship.

\section{Abbreviations}

IC, invasive candidiasis; NPV, negative predictive value; PPV, positive predictive value.

\section{Competing interests}

LO receives research funding and is a consultant and speaker for Merck \& Co.,

Pfizer, and Astellas. He receives research funding from Associates of Cape Cod.

Published: 22 September 2011

\section{References}

1. Hermsen ED, Zapapas MK, Maiefski M, Rupp ME, Freifeld AG, Kalil AC: Validation and comparison of clinical prediction rules for invasive candidiasis in intensive care unit patients: a matched case-control study. Crit Care 2011, 15:R198.

2. Wisplinghoff H, BischoffT, Tallent SM, Seifert H, Wenzel RP, Edmond MB: Nosocomial bloodstream infections in US hospitals: analysis of 24,179 cases from a prospective nationwide surveillance study. Clin Infect Dis 2004 39:309-317.

3. Rentz AM, Halpern MT, Bowden R: The impact of candidemia on length of hospital stay, outcome, and overall cost of illness. Clin Infect Dis 1998 27:781-788

4. Eggimann P, Ostrosky-Zeichner L: Early antifungal intervention strategies in ICU patients. Curr Opin Crit Care 2010, 16:465-469.
5. Ostrosky-Zeichner L, Kullberg BJ, Bow EJ, Hadley S, Leon C, Nucci M, Patterson TF, Perfect JR: Early treatment of candidemia in adults: a review. Med Mycol 2011, 49:113-120.

6. Paphitou NI, Ostrosky-Zeichner L, Rex JH: Rules for identifying patients at increased risk for candidal infections in the surgical intensive care unit: approach to developing practical criteria for systematic use in antifungal prophylaxis trials. Med Mycol 2005, 43:235-243.

7. Ostrosky-Zeichner L, Sable C, Sobel J, Alexander BD, Donowitz G, Kan V, Kauffman CA, Kett D, Larsen RA, Morrison V, Nucci M, Pappas PG, Bradley ME, Major S, Zimmer L, Wallace D, Dismukes WE, Rex JH: Multicenter retrospective development and validation of a clinical prediction rule for nosocomial invasive candidiasis in the intensive care setting. Eur J Clin Microbiol Infect Dis 2007, 26:271-276.

8. Leon C, Ruiz-Santana S, Saavedra P, Almirante B, Nolla-Salas J, Alvarez-Lerma F, Garnacho-Montero J, Leon MA: A bedside scoring system ("Candida score") for early antifungal treatment in nonneutropenic critically ill patients with Candida colonization. Crit Care Med 2006, 34:730-737

9. León C, Ruiz-Santana S, Saavedra P, Galván B, Blanco A, Castro C, Balasini C, Utande-Vázquez A, González de Molina FJ, Blasco-Navalproto MA, López MJ, Charles PE, Martín E, Hernández-Viera MA; Cava Study Group: Usefulness of the "Candida score" for discriminating between Candida colonization and invasive candidiasis in non-neutropenic critically ill patients: a prospective multicenter study. Crit Care Med 2009, 37:1624-1633.

10. Ostrosky-Zeichner L, Pappas PG, Shoham S, Reboli A, Barron MA, Sims C Wood C, Sobel JD: Improvement of a clinical prediction rule for clinical trials on prophylaxis for invasive candidiasis in the intensive care unit. Mycoses 2011, 54:46-51.

doi: $10.1186 /$ cc10422

Cite this article as: Ostrosky-Zeichner L: Clinical prediction rules for invasive candidiasis in the ICU: ready for prime time? Critical Care 2011, 15:189. 